\title{
Penerapan Metode Taguchi pada Perancangan Eksperimen Beton Geopolimer Berbasis Abu Layang
}

\author{
Ufafa Anggarini $^{1 *}$, Claudia Kosada ${ }^{2}$, Ndaru Candra Sukmana ${ }^{2}$ \\ ${ }^{1}$ Program Studi Teknik Kimia FTIA UISI, Kampus A, Jl. Veteran, Kompleks PT Semen Indonesia, 61122 \\ ${ }^{2}$ Program Studi Manajemen Rekayasa FTIA UISI, Kampus A, Jl. Veteran, Kompleks PT Semen Indonesia, \\ 61122 \\ email: ufafa.anggarini@uisi.ac.id
}

\begin{abstract}
PT Petrokima Gresik produces fly ash from coal burning about 8048,89 tons in 2015. In general, one ton of coal burning can produce around 0.15 to 0.17 tons of fly ash waste. Fly ash waste can be utilized as a mixture where the main elements of fly ash are aluminum and silica, fulfilling criteria as the material having cement and geopolymer properties. Geopolymer preparation can be done by the sol-gel method at low temperature, where the emission of $\mathrm{CO}_{2}$ gas produced is a minimum amount. The problem faced is finding the right composition of geopolymer so that it produces the maximum compressive strength. One way is by designing a Taguchi experiment. The choice of the Taguchi method is based on the advantages of this method that can combine experimental results through controlled factors and optimal levels so it can achieve the maximum compressive strength of geopolymer. This research used 3 levels $(-1,0,1)$ and 4 factors of fly ash, the solid/liquid ratio (SL), the molarity of $\mathrm{NaOH}(A)$, Sand/pasta geopolymer ratio (P/PG). Anova test showed significant effect on compressive strength of fly ash, $S / L$ and $A$ with value of 12,27>2,90; 61,12> 2,$90 ; 19,477>2,90$. While the value for $P / P G$ is $1.92<2.90$ where the value of $F$-statistic is less than $F$ table which means $P$ / PG does not significantly affect the compressive strength of Geopolymer. With $S / N$ higher is better to know the optimum composition of fly ash, S / L, A and P / PG equal to: 370 gram; 2.33 (70:30); 9 Molar, and 1.5. The prediction of Geopolymer maximum compressive strength with Taguchi method was obtained 18,71 Mpa.
\end{abstract}

Keywords: Fly ash, Optimation, Taguchi, Geopolymer

\section{Pendahuluan}

Penggunaan batu bara dalam pemenuhan kebutuhan akan energi terus meningkat sejalan dengan peningkatan jumalah penduduk setiap tahunnya. Pusat Penelitian dan Pengembangan Teknologi Mineral dan Batu Bara pada tahun 2009 melaporkan bahwa pada tahun 2000 - 2007 konsumsi batu bara cenderung meningkat yaitu sebesar 22.340.845 ton pada tahun 2000 dan meningkat mencapai 61.470.000 ton pada tahun 2007 [1]. Berdasarkan data Laporan Kinerja Direktorat Jendral Mineral dan Batubara pada tahun 2016, target produksi batubara sebesar 419 juta ton telah terealisasi sebesar 434 juta ton (persentase capaian 103,57\%) pada tahun tersebut menunjukkan peningkatan konsumsi batubara di tanah air [2]. Tingginya konsumsi batu bara ini dipengaruhi oleh banyaknya industri yang menggunakan sumber daya alam ini untuk pemenuhan energi, diantaranya yaitu pembangkit listrik, industri keramik dan semen, industri kertas, industri logam, industri briket, dll [3]. Dalam penggunaan batubara sebagai sumber energi, dihasilkan limbah berupa abu layang (fly ash), abu dasar (bottom ash) dan gas $\mathrm{CO}_{2}$. Satu ton batu bara jika dibakar menghasilkan sekitar 0,15 hingga 0,17 ton limbah abu layang [4]. PT Petrokima Gresik sebagai salah satu industri yang menggunakan batu bara dalam pemenuhan energinya, menghasilkan abu layang mencapai 8048,89 ton pada tahun 2015 [5].

Wang dan Zhua [6] menyatakan bahwa pemanfaatan abu layang telah mendapatkan banyak perhatian oleh masyarakat dan industri, hal ini dikarenakan ketersediaan limbah abu layang yang melimpah sehingga dapat menjadi alternatif bahan baku yang ekonomis. Anggarini dan Sukmana [7] menyatakan bahwa salah satu pemanfaatan abu layang yaitu sebagai campuran semen, bahan pembuatan zeolit, karbon aktif dan geopolimer. Penggunaan abu layang telah sampai pada proses industri semen dan konstruksi yaitu sebagai bahan baku tambahan ataupun campuran. Pemanfaatan abu layang lainnya dapat dilakukan melalui pengolahan abu layang menjadi geopolimer dikarenakan adanya kandungan mineral dan $\mathrm{Al}_{2} \mathrm{O}_{3}$ serta $\mathrm{SiO}_{2}$. Geopolimer adalah kelompok bahan yang menyerupai keramik yang dibentuk oleh reaksi geosintesis mineral alumino-silikat dengan larutan alkali pada suhu rendah kurang dari $100^{\circ} \mathrm{C}$ (Wang dan Zhua, 2007) [6]. Davidovits [8] menjelaskan bahwa geopolimer dapat difungsikan sebagai pengikat mineral dengan kuat tekan tinggi. Pada penelitian Chindaprasirt, et.al. [9], diketahui bahwa molaritas aktivator dapat mempengaruhi 
pembentukan dan kuat tekan geopolimer. Tavor, et.al. [10] dalam penelitiannya menjelaskan bahwa kuat tekan geopolimer meningkat sejalan dengan meningkatnya molaritas $\mathrm{NaOH}$ dan waktu curing, kuat tekan menurun sejalan dengan meningkatnya penambahan air dalam campuran geopolimer, dan peningkatan temperatur curing dari $60{ }^{\circ} \mathrm{C}$ ke $90{ }^{\circ} \mathrm{C}$ dapat meningkatkan kuat tekan geopolimer. Penelitian lainnya, Nath, et.al. [11] menyatakan bahwa temperatur curing geopolimer dapat dilakukan pada suhu ruang yaitu $23^{\circ} \mathrm{C}$, tambahan pasir dapat meningkatkan kuat tekan geopolimer.

Berdasarkan beberapa penelitian diatas, pada penelitian ini dilakukan variasi pembuatan geopolimer berbahan dasar abu layang PT Petrokimia Gresik untuk menentukan pengaruh variabel pada kekuatan geopolimer. Variabel yang digunakan dalam penelitian ini adalah banyaknya abu layang, rasio padatan/air, molaritas aktivator $\mathrm{NaOH}$ dan rasio pasir/pasta geopolimer. Evaluasi pengaruh variabel beton goepolimer secara statistik perlu diuji dengan perancangan eksperimen metode taguchi. Eksperimen taguchi dapat dilakukan dengan menentukan faktor yang terkendali dan faktor yang tidak terkendali. Dipilihnya metode taguchi didasarkan pada kelebihan metode ini yang dapat mengkombinasikan hasil eksperimen melalui faktor yang terkendali dan level yang optimal. Metode ini juga dapat mengurangi jumlah pelaksanaan percobaan sehingga dapat menghemat waktu dan biaya penelitian [12].

\section{Metodologi}

\section{Perancangan Eksperimen}

\section{Penentuan Karakteristik Kualitas}

Berdasarkan metode taguchi terdapat tiga karakteristik kualitas yaitu : nominal is the best, large is better dan higher is better. Karakteristik berdasarkan metode taguchi yang sesuai dengan penelitian yaitu higher is better, karena hasil dari penelitian ini yaitu berupa kuat tekan yang tinggi. Hal ini dikarenakan semakin tinggi nilai kuat tekan maka akan semakin baik kualitas beton geopolimer yang dihasilkan. Higher is better merupakan karakteristik terukur dengan nilai non negatif dengan nilai ideal tak terhingga. Pada Persamaan 1 dapat diketahui rumus $\mathrm{S} / \mathrm{N}$ untuk perhitungan higher is better. Nilai $\mathrm{S} / \mathrm{N}$ untuk karakteristik kualitas higher is better adalah :

$$
S / N=-10 \log _{10}\left[\frac{1}{n} \sum_{i=1}^{n} \frac{1}{y^{2}}\right]
$$

Dengan $\mathrm{n}$ adalah banyaknya ulangan dalam tiap eksperimen dan y adalah nilai pada setiap run.

\section{Penentuan Level, Faktor dan Orthogonal Array (OA)}

Adapun faktor yang diambil yaitu; abu layang, rasio padatan/air (S/L), molaritas $\mathrm{NaOH}(\mathrm{A})$, rasio pasir/pasta geopolimer (P/PG), maka terdapat 4 faktor $(\mathrm{k}=4)$. Level 0 sebagai acuan berasal dari penelitian terdahulu sebagai berikut: Abu layang $=370$ gram $; \mathrm{S} / \mathrm{L}=70: 30 ; \mathrm{A}=9 \mathrm{M} ; \mathrm{P} / \mathrm{PG}=1: 1$, untuk level -1 dan +1 dapat dilihat pada Tabel 1. OA dengan 3 level dan 4 faktor maka matriksnya adalah L934 artinya yaitu ada 9 variasi percobaan dengan 4 faktor dan 3 level yang dapat dilihat pada Tabel 2.

Tabel 1. Faktor dan Level Beton Geopolimer

\begin{tabular}{|c|c|c|c|c|}
\hline \multirow{2}{*}{ Level } & \multicolumn{4}{|c|}{ Faktor } \\
\cline { 2 - 5 } & $\begin{array}{c}\text { Abu Layang } \\
\text { (gram) }\end{array}$ & $\begin{array}{c}\text { S/L } \\
\text { (gram) }\end{array}$ & $\begin{array}{c}\text { A } \\
\text { (Molar) }\end{array}$ & $\begin{array}{c}\text { P/PG } \\
\text { (gram) }\end{array}$ \\
\hline-1 & 270 & $60: 40$ & 7 & $1,5: 1$ \\
\hline 0 & 370 & $70: 30$ & 9 & $1: 1$ \\
\hline+1 & 470 & $80: 20$ & 11 & $0,5: 1$ \\
\hline
\end{tabular}

Tabel 2. Orthogonal Array Beton Geopolimer

\begin{tabular}{|c|c|c|c|c|}
\hline Run & Abu Layang & S/L & A & P/PG \\
\hline 1 & 270 & $60: 40$ & 7 & 1,5 \\
\hline 2 & 270 & $70: 30$ & 9 & 1 \\
\hline 3 & 270 & $80: 20$ & 11 & 0,5 \\
\hline 4 & 370 & $60: 40$ & 9 & 0,5 \\
\hline 5 & 370 & $70: 30$ & 11 & 1,5 \\
\hline 6 & 370 & $80: 20$ & 7 & 1 \\
\hline 7 & 470 & $60: 40$ & 11 & 1 \\
\hline 8 & 470 & $70: 30$ & 7 & 0,5 \\
\hline 9 & 470 & $80: 20$ & 9 & 1,5 \\
\hline
\end{tabular}




\section{Sintesis Geopolimer dan Pengujian Kuat Tekan}

Persiapan bahan baku dilakukan dengan mengayak pasir dan abu layang terlebih dahulu untuk mendapatkan keseragaman ukuran partikel. Material awal yang digunakan dalam penelitian ini adalah larutan natrium silikat dan abu layang PT Petrokimia Gresik sebagai sumber aluminosilikat. Larutan alkali dipersiapkan dengan cara mencampurkan larutan $\mathrm{NaOH}$ molaritas tertentu dengan natrium silikat. Larutan alkali yang dihasilkan kemudian didinginkan dalam penangas es. Pada penelitian ini dilakukan variasi seperti tertera pada Tabel 2. Bahan baku abu layang direaksikan dengan larutan alkali hingga homogen membentuk pasta geopolimer dan siap untuk dicetak dan dicuring pada suhu ruang selama 28 hari. Penggujian kuat tekan dilakukan pada mesin tekan secara simetris dengan penambahan beban yang konstan berkisar antara 2-4 $\mathrm{kg} / \mathrm{cm} 2$ per detik. Pembebanan dilakukan hingga benda uji hancur dan beban maksimum dicatat. Hasil dari pengujian berupa nilai kuat tekan (P), disebut sebagai respon (Mpa). Data hasil uji kuat tekan diolah untuk menemukan komposisi optimum. Data diolah dengan memplot data nilai S/N sehingga diperoleh komposisi optimum tiap faktor. Data hasil kuat tekan/respon $(\mathrm{P})$ dihitung kuat tekan rata-rata $(\overline{\mathrm{P}})$ seperti pada Persamaan 2 dan nilai $\mathrm{S} / \mathrm{N}$ higher is better pada Persamaan 1.

$$
\overline{\mathrm{P}}=\frac{\sum \text { Kuat Tekan }}{\text { Banyaknya data }}
$$

\section{Penentuan Faktor Berpengaruh}

Hasil uji kuat tekan diolah dengan analysis of variance (ANOVA) pada software MINITAB. Dari hasil ANOVA akan diketahui apakah hipotesa $\left(\mathrm{H}_{0}\right)$ diterima atau ditolak serta akan didapatkan faktor-faktor yang signifikan mempengaruhi kuat tekan dari beton geopolimer. Faktor tersebut dilakukan uji homogenitas dan normalitas jika data $>\alpha(\alpha: 0,05)$ berarti data adalah data homogen dan normal. Selanjutnya dilakukan uji ANOVA jika data $>\alpha(\alpha: 0,05)$ yang berarti terima $\mathrm{H}_{0}$.

\section{Hasil dan Pembahasan}

\section{Penentuan Variabel yang Berpengaruh}

Pengaruh variabel penelitian dalam pembuatan beton geopolimer dianalisis dengan uji ANOVA. Pengujian normalitas sebelumnya dilakukan untuk menentukan distribusi data yang diperoleh. Uji normalitas dilakukan dengan dua hipotesa yaitu $\mathrm{H}_{0}$ merupakan hipotesa yang menyatakan bahwa data sampel uji kuat tekan beton geopolimer berdistribusi normal sedangkan $\mathrm{H}_{1}$ merupakan hipotesa yang menyatakan bahwa data sampel uji kuat tekan beton geopolimer tidak berdistribusi normal. Hipotesa awal $\left(\mathrm{H}_{0}\right)$ akan diterima jika nilai P-Value > 0,05. Tabel 3 menunjukkan hasil uji normalitas kolmogorov-smirnov. Berdasarkan tabel tersebut, diketahui bahwa P-Value bernilai 0,083 yang mana lebih besar dari 0,05. Sehingga, data hasil pengujian kuat tekan beton geopolimer pada penelitian ini berdistribusi normal. Uji ANOVA selanjutnya dilakukan untuk mengetahui pengaruh setiap faktor terhadap kuat tekan beton geopolimer dengan melihat hasil uji kuat tekan beton geopolimer. Uji ANOVA dilakukan dengan dua hipotesa yaitu $\mathrm{H}_{0}$ yang menyatakan bahwa $\tau 1=\tau 2=0$ (Komposisi tidak berpengaruh terhadap kuat tekan beton geopolimer) dan $\mathrm{H}_{1}$ yang menyatakan bahwa $\tau 1 \neq 0$ (Komposisi berpengaruh terhadap kuat tekan beton geopolimer). Hipotesa awal akan ditolak apabila nilai Fstatistik $>\mathrm{F} \propto$, df-num, df-den. Dengan $\propto$ adalah tingkat kepercayaan 5\%, df-num adalah derajat kebebasan yang digunakan sebagai pembilang, df-den adalah derajat kebebasan yang digunakan sebagai penyebut.

Tabel 3. Hasil Uji Normalitas

\begin{tabular}{|l|l|l|}
\hline \multicolumn{2}{|l|}{} & \multicolumn{1}{|c|}{ Kuat Tekan } \\
\hline $\mathrm{N}$ & Normal Parameters ${ }^{\mathrm{a}}$ & 36 \\
\cline { 3 - 4 } & Std. Deviation & 4.74802 \\
\hline \multirow{3}{*}{ Most Extreme Differences } & Absolute & .210 \\
\cline { 2 - 3 } & Positive & .210 \\
\cline { 2 - 3 } & Negative & -.165 \\
\hline Kolmogorov-Smirnov Z & 1.260 \\
\hline Asymp. Sig. (2-tailed) & .083 \\
\hline
\end{tabular}

a. Test distribution is Normal. 
Hasil uji ANOVA seperti tertera pada Tabel 4 dapat disimpulkan bahwa nilai $\mathrm{F}$ dari abu layang, rasio solid/liquid (S/L), molaritas $\mathrm{NaOH}(\mathrm{A})$ adalah lebih besar dibandingkan dengan $\mathrm{F}$ tabel. Hasil nilai $\mathrm{F}$ untuk abu layang sebesar 12,27 > 2,90 (nilai F tabel) untuk S/L sebesar 61,12 >2,90 untuk A sebesar 19,477 > 2,90 hasil ini menunjukkan bahwa komposisi abu layang, S/L dan A memiliki pengaruh signifikan terhadap nilai kuat tekan dari beton geopolimer. Sedangkan nilai untuk pasir/ pasta geopolimer yaitu 1,92<2,90 dimana nilai F statistik kurang dari F tabel yang berarti faktor pasir/pasta geopolimer tidak signifikan mempengaruhi kuat tekan beton geopolimer. Rasio solid/liquid (S/L) memiliki nilai $\mathrm{F}$ statistik terbesar yang berarti komposisi S/L memiliki pengaruh terbesar terhadap kuat tekan beton geopolimer.

Tabel 4. Nilai Uji ANOVA

\begin{tabular}{|c|c|c|c|c|}
\hline \multicolumn{5}{|c|}{ Factor Information } \\
\hline Faktor & & Tipe & & Nilai \\
\hline Abu layang & & Fixed & & $270 ; 370 ; 470$ \\
\hline $\mathrm{S} / \mathrm{L}$ & & Fixed & & 1,$5 ; 2,333 ; 4,0$ \\
\hline A & & Fixed & & $7 ; 9 ; 11$ \\
\hline $\mathrm{P} / \mathrm{PG}$ & & Fixed & & 0,$5 ; 1,0 ; 1,5$ \\
\hline \multicolumn{5}{|c|}{ Analisa Varian } \\
\hline Sumber & $\mathrm{DF}$ & Adj SS & Adj MS & Nilai F \\
\hline Abu layang & 2 & \multirow{2}{*}{$\begin{array}{c}89,39 \\
445,42\end{array}$} & \multirow{2}{*}{44,693} & \multirow[b]{2}{*}{12,27} \\
\hline $\mathrm{S} / \mathrm{L}$ & 2 & & & \\
\hline A & 2 & 141,86 & $\begin{array}{c}222,708 \\
70,932\end{array}$ & 61,12 \\
\hline $\mathrm{P} / \mathrm{PG}$ & 2 & 13,98 & \multirow{2}{*}{6,992} & 19,47 \\
\hline Error & 27 & \multirow{2}{*}{$\begin{array}{c}98,33 \\
780\end{array}$} & & 1,92 \\
\hline Total & 35 & & 3,644 & \\
\hline
\end{tabular}

\section{Kuat Tekan Geopolimer Berbasis Abu Layang}

Abu layang PT Petrokimia Gresik dalam penelitian ini digunakan sebagai sumber aluminosilikat dengan komposisi seperti tertera pada Tabel 5. Hasil pengujian diperoleh dengan instrumen XRF, selanjutnya digunakan untuk memperhitungkan persentase penambahan bahan baku abu layang dengan larutan aktivator untuk menghasilkan pasta geopolimer. Berdasarkan hasil pengujian XRF, dikonfirmasi bahwa abu layang mengandung oksida $\mathrm{SiO}_{2}$ dan $\mathrm{Al}_{2} \mathrm{O}_{3}$ dalam jumlah yang melimpah yang potensial digunakan sebagai sumber aluminosilikat geopolimer.

Tabel 5. Persen Berat Oksida Abu Layang PT Petrokimia Gresik

\begin{tabular}{ccc}
\hline No. & Oksida & \% berat \\
\hline 1 & $\mathrm{Al}_{2} \mathrm{O}_{3}$ & 27,11 \\
2 & $\mathrm{CaO}$ & 9,07 \\
3 & $\mathrm{Fe}_{2} \mathrm{O}_{3}$ & 6,18 \\
4 & $\mathrm{~K}_{2} \mathrm{O}$ & 1,49 \\
5 & $\mathrm{MgO}$ & 3,18 \\
6 & $\mathrm{Na}_{2} \mathrm{O}$ & 0,59 \\
7 & $\mathrm{P}_{2} \mathrm{O}_{5}$ & 4,24 \\
8 & $\mathrm{SiO}_{2}$ & 46,93 \\
\hline
\end{tabular}

Berdasarkan hasil pengujian kuat tekan pada 28 hari, diperoleh nilai kuat tekan beton geopolimer untuk keempat repikasi (R-1, R-2, R-3, R-4). Nilai kuat tekan dari keempat replikasi selanjutnya dihitung rata-rata kuat tekan menggunakan Persamaan 2. Nilai kuat tekan juga digunakan untuk perhitungan nilai $\mathrm{S} / \mathrm{N}$ sebagaimana terlihat pada Tabel 4 berikut yang merupakan hasil olahan dari software minitab. Nilai rata-rata S/N pada setiap faktor dan level kemudian diplot seperti tertera pada Gambar 1. Pada Gambar 1 dapat dilihat bahwa titik puncak pada setiap faktor yaitu : abu layang bernilai 370; S/L bernilai 2,33 (70:30); A bernilai 9, $\mathrm{P} / \mathrm{PG}$ bernilai 1,5. Dengan S/N higher is better, nilai titik puncak ini menandakan tingkat optimum oleh setiap faktor yang diujikan yang selanjutnya disebut sebagai kompisisi optimum [13]. Komposisi optimum tiap faktor selajutnya dilihat nilai kuat tekan dan juga $\mathrm{S} / \mathrm{N}$ pada tiap komposisi seperti terlihat pada Tabel 6 , dan ditentukan rata-rata pada masing-masing level untuk memprediksi kuat tekan optimum dan S/N optimum. Perhitungan Kuat Tekan dan S/N prediksi sesuai dengan persamaan 3 dan 4. Berdasarkan hasil, perhitungan didapatkan kuat tekan prediksi sebesar 18,71 Mpa dan S/N prediksi sebesar 33,19.

$$
\begin{aligned}
& P_{\text {prediksi }}=\overline{\mathrm{FA}}+\frac{\overline{\mathrm{S}}}{\mathrm{L}} \overline{\mathrm{A}}+\frac{\overline{\mathrm{P}}}{\mathrm{PG}}-(2 * \overline{\overline{\mathrm{P}}}) \\
& S / N R_{\text {prediksi }}=\overline{\mathrm{S} / \mathrm{NR}_{F A}}+\overline{S / N R_{S / L}}+\overline{S / N R_{A}}+\overline{S / N R_{\mathrm{P} / \mathrm{PG}}}-(2 * \overline{\overline{S / N R}})
\end{aligned}
$$


Tabel 6. Hasil Kuat Tekan Geopolimer 28 hari

\begin{tabular}{ccccccccccc}
\hline Run & $\begin{array}{c}\text { Abu } \\
\text { Layang }\end{array}$ & S/L & $\mathbf{A}$ & $\mathbf{P} / \mathbf{P G}$ & $\begin{array}{c}\mathbf{R - 1} \\
(\mathbf{M p a})\end{array}$ & $\begin{array}{c}\mathbf{R}-2 \\
(\mathbf{M p a})\end{array}$ & $\begin{array}{c}\mathbf{R}-3 \\
(\mathbf{M p a})\end{array}$ & $\begin{array}{c}\mathbf{R}-4 \\
(\mathbf{M p a})\end{array}$ & $\begin{array}{c}\overline{\mathbf{P}} \\
(\mathbf{M p a})\end{array}$ & $\mathbf{S} / \mathbf{N}$ \\
\hline 1 & 270 & $60: 40$ & 7 & 1,5 & 1,32 & 1,3 & 1,2 & 1,4 & 1,31 & 2,2726 \\
2 & 270 & $70: 30$ & 9 & 1 & 14,2 & 15 & 18,6 & 12 & 14,9 & 23,178 \\
3 & 270 & $80: 20$ & 11 & 0,5 & 4,9 & 4,9 & 6 & 5,3 & 5,28 & 14,357 \\
4 & 370 & $60: 40$ & 9 & 0,5 & 6,7 & 5,2 & 6,9 & 5,3 & 6,03 & 15,381 \\
5 & 370 & $70: 30$ & 11 & 1,5 & 18,3 & 10,2 & 9,1 & 9,2 & 11,7 & 20,399 \\
6 & 370 & $80: 20$ & 7 & 1 & 2,5 & 2,3 & 2 & 2,3 & 2,27 & 7,0549 \\
7 & 470 & $60: 40$ & 11 & 1 & 3 & 3 & 3 & 1,8 & 2,70 & 7,9454 \\
8 & 470 & $70: 30$ & 7 & 0,5 & 4,8 & 4,6 & 8,5 & 5 & 5,72 & 14,421 \\
9 & 470 & $80: 20$ & 9 & 1,5 & 2,4 & 3 & 1,2 & 3 & 2,40 & 5,6452 \\
\hline
\end{tabular}

\section{Main Effects Plot for SN ratios}

\section{Data Means}

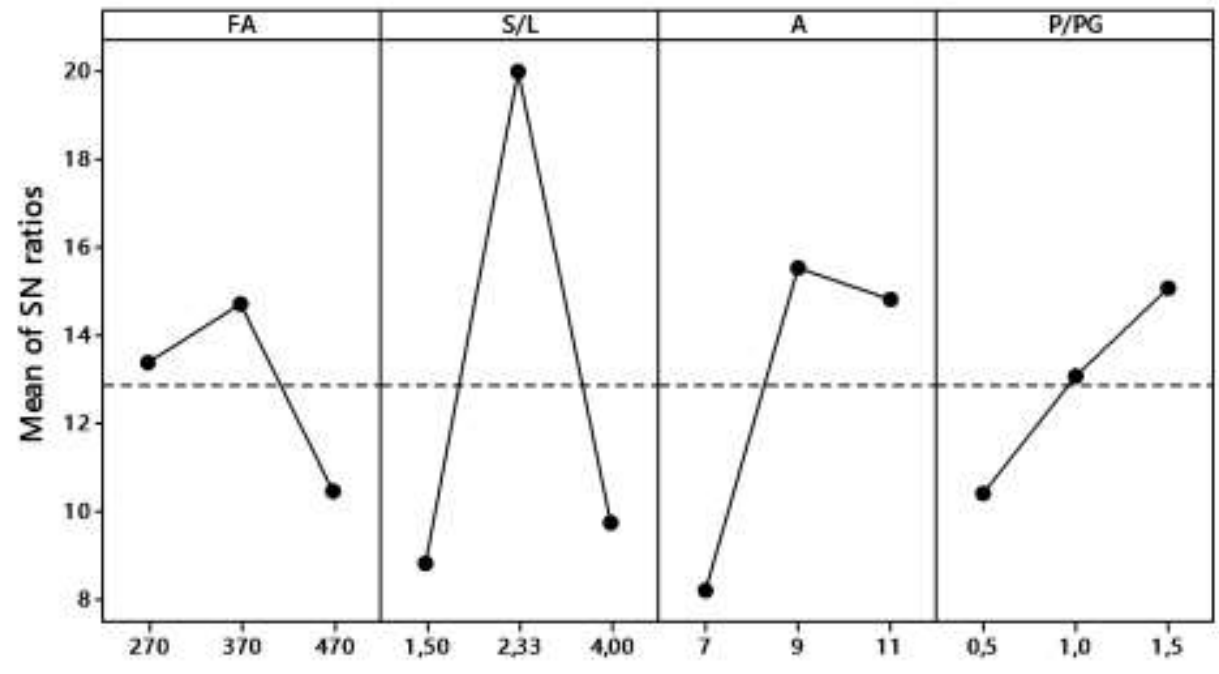

Signal-to-noise Larger is better

Gambar 1. Nilai S/N

\section{Kesimpulan}

Komposisi optimum campuran beton geopolimer berbasis abu layang yaitu abu layang bernilai 370; S/L bernilai 2,33 (70:30); A bernilai 9, P/PG bernilai 1,5. Faktor yang mempengaruhi kuat tekan beton geopolimer berbasis abu layang secara signifikan adalah abu layang, rasio padatan/air (S/L) dan molaritas $\mathrm{NaOH}$ (A). Sedangkan faktor pasir/ pasta geopolimer tidak signifikan mempengaruhi kuat tekan beton geopolimer. Dengan menggunakan optimasi metode Taguchi dapat diprediksi kuat tekan geopolimer dapat ditingkatkan hingga maksimal 18,71 Mpa.

\section{Ucapan Terimakasih}

Penulis memberikan ucapan terimakasih kepada LPPM UISI yang telah memberikan Hibah Riset Terapan dibawah program Hibah Riset Tahun 2017 dengan nomor kontrak 02/KP.03/11-01/05.17 tanggal 1 maret 2017.

\section{Daftar Pustaka}

[1]. BPPT. 2016. Outlook Energi Indonesia 2016, ISBN 978-602-74702-0-0.

[2]. -,2015. Limbah dan Pemanfaatan Abu Batubara. www.pusdiklat-minerba.esdm.go.id, 21 Januari 2017 
[3]. Khaerunisa, H., Huda, M. \& Damayanti, R.. 2009. Kajian Emisi $\mathrm{CO}_{2}$ dari Pembakaran Batu Bara di Indonesia. Pusat Penelitian dan Pengembangan Teknologi Mineral dan Batubara, Indonesia.

[4]. Safitri, D.E. 2009. Kajian Teknis dan Kajian Ekonomis Pemanfaatan Limbah Batubara (Fly Ash) pada Produksi Paving Block. Media Teknik Sipil. 9: 36-40.

[5]. -,2016. Laporan Tahunan Pupuk Indonesia 2016. http://pupuk-indonesia.com, 17 Januari 2017

[6]. Wang, S., Li, L. \& Zhua, Z.H. 2007. Solid-state conversion of fly ash to effective adsorbents for $\mathrm{Cu}$ removal from wastewater. Journal of Hazardous Materials. 139 : 254-259.

[7]. Anggarini, U. \& Sukmana, N.C. 2016. Synthesis and Characterization of Geopolymer from Bottom Ash and Rice Husk Ash. IOP Conf. Series: Materials Science and Engineering. 107: 012-022.

[8]. Davidovits, J. 2015. Geopolymer Chemistry and Applications. $3^{\text {rd }}$ Edition In J. Davidovits, ed. Polymers and Geopolymers. Institut Géopolymère. France.

[9]. Chindaprasirt, P., Jaturapitakkul, C., Chalee, W. \& Rattanasak, U. 2008. Comparative Study on The Characteristics of Fly Ash and Bottom Ash Geopolymers. Waste Management. 29: 539-43.

[10]. Tavor, D., Wolfson, A. \& Shamaev, A. 2007. Recycling of Industrial Wastewater by Its Immobilization in Geopolymer Cement. Ind. Eng. Chem. Res. 4: 6801-6805.

[11]. Nath, Pradip, Saker, Prabir Kumar, Rangan, Vijaya B. 2015. Early Age Properties of Low-Calcium Fly Ash Geopolymer Concrete Suitable for Ambient Curing. Procedia Engineering. 125: 601-607

[12]. Muharom \& Siswadi. 2015. Desain Eksperimen Taguchi Untuk Meningkatkan Kualitas Batubata Berbahan Baku Tanah Liat. Jemis. 3: 43-46.

[13]. Hartono, M., 2012. Meningkatkan Mutu Produk Plastik dengan Metode Taguchi. Jurnal Teknik Industri. 13: 93-100. 